\title{
Teaching with Information Texts: Comparing the Beliefs of Malaysian and New Zealand Trainers
}

\author{
John Macalister \\ Victoria University of Wellington, New Zealand
}

\begin{abstract}
This paper investigates the approaches to teaching an information text proposed by two groups of trainers involved in the same Malaysian pre-service teacher training programme. Qualitative data analysis was used on transcribed interviews with the trainers. There were both similarities and differences between the Malaysian and New Zealand trainer responses, and the differences appear to suggest that the distinction in language teaching as practised and promoted in Britain, Australasia and North America and found in tertiary, secondary and primary sectors throughout the world (the BANA / TESEP distinction) remains valid twenty years after it was first proposed. An awareness of such differences is important for teachers, teacher trainers, and curriculum / material designers working in contexts where the BANA / TESEP approaches to language teaching meet.
\end{abstract}

Various approaches have been proposed for thinking about the English language and English language learning around the world. A particularly influential model for understanding English globally has been Kachru's idea of the three circles (Kachru, 1985), with the inner consisting of countries where English is the native language, the outer circle, countries where English operates as a second language, and the expanding circle, countries in which English is learned and used as a foreign language. Within English language learning, a powerful construct has been the distinction between the acronyms BANA and TESEP (Holliday, 1994), where BANA stands for the approach to language learning and teaching practised and promoted in Britain, Australasia and North America and TESEP for the approach found in tertiary, secondary and primary sectors throughout the world. It is important to emphasise that TESEP is practised in BANA countries - Kachru's inner circle - as well as the outer and expanding circle countries. Similarly, BANA practices can be found in otherwise TESEP environments, such as in the teaching at a private language provider.

The distinguishing characteristics of BANA and TESEP, following Holliday (1994), are set out in Table 1. In essence, the BANA approach tends to be more learner-responsive and learnercentred and less curricularly constrained than TESEP. Because those who research and write about language acquisition and language teaching methodology - those who determine what is "good" and what is not - tend to come from the English-speaking West, the BANA approach is regarded as having higher status than that of TESEP. 
Table 1

Characteristics of BANA and TESEP Approaches (Holliday, 1994)

\begin{tabular}{|l|l|}
\hline \multicolumn{1}{|c|}{ BANA } & \multicolumn{1}{c|}{ TESEP } \\
\hline • Instrumental orientation & - State orientation \\
$\bullet$ Learner-centred & $\bullet$ Teacher-centred \\
$\bullet$ Communicative & $\bullet$ Grammar translation \\
$\bullet$ High status & - Low status \\
$\bullet$ Innovation \& dynamism & Static \\
\hline
\end{tabular}

The distinction between BANA / TESEP is not unproblematic, of course, and has been misunderstood to some extent (Holliday, 2001). It is also not the only possible way of thinking about different approaches - others include the Centre / Periphery distinction and the native versus non-native speaker debate (Holliday, 2001). But what all have in common is that one component emanates from the inner circle, the other from the outer and expanding circles. Furthermore, this distinction has been found useful in understanding the challenges that can exist when proposing changes in particular learning contexts (e.g., Julian \& Foster, 2011; Leather, 2001).

\section{Developing Teacher Cognition}

The context for this study is a pre-service teacher training programme in which Malaysian trainees receive training in both Malaysia and New Zealand; in other words, they receive training in both inner and outer circle contexts where BANA / TESEP distinctions may exist. The structure of the programme is outlined in Table 2. Thus, both Malaysian and New Zealand-based trainers are likely to be contributing to the developing cognition of these teacher trainees.

\section{Table 2}

\section{Overview of Teacher Training Programme}

\begin{tabular}{|c|}
\hline \multicolumn{1}{|c|}{ Degree Programme Structure } \\
\hline$\bullet 2 \frac{1}{2} 2$ years in Malaysia (Foundation + first year) \\
- 2 years in a New Zealand or other BANA university \\
- final year in Malaysia \\
\hline
\end{tabular}

Teacher cognition, as shown in Figure 1, is subject to a number of influences. These include previous experiences, professional coursework and beliefs, attitudes, and knowledge (BAK). As an example, a teacher may enjoy reading in her first language in her free time and so she is likely to hold positive attitudes to reading. In her teacher training, she may have learned that reading for pleasure is useful for language learning. This knowledge is likely to reinforce her already positive attitudes to reading, and the cumulative effect on her teacher cognition is probably going to result in a wish to incorporate reading into her teaching practice. Whether, in fact, this cognition does translate into classroom practice may depend on, for example, the availability of books - the context. 


\section{Research}

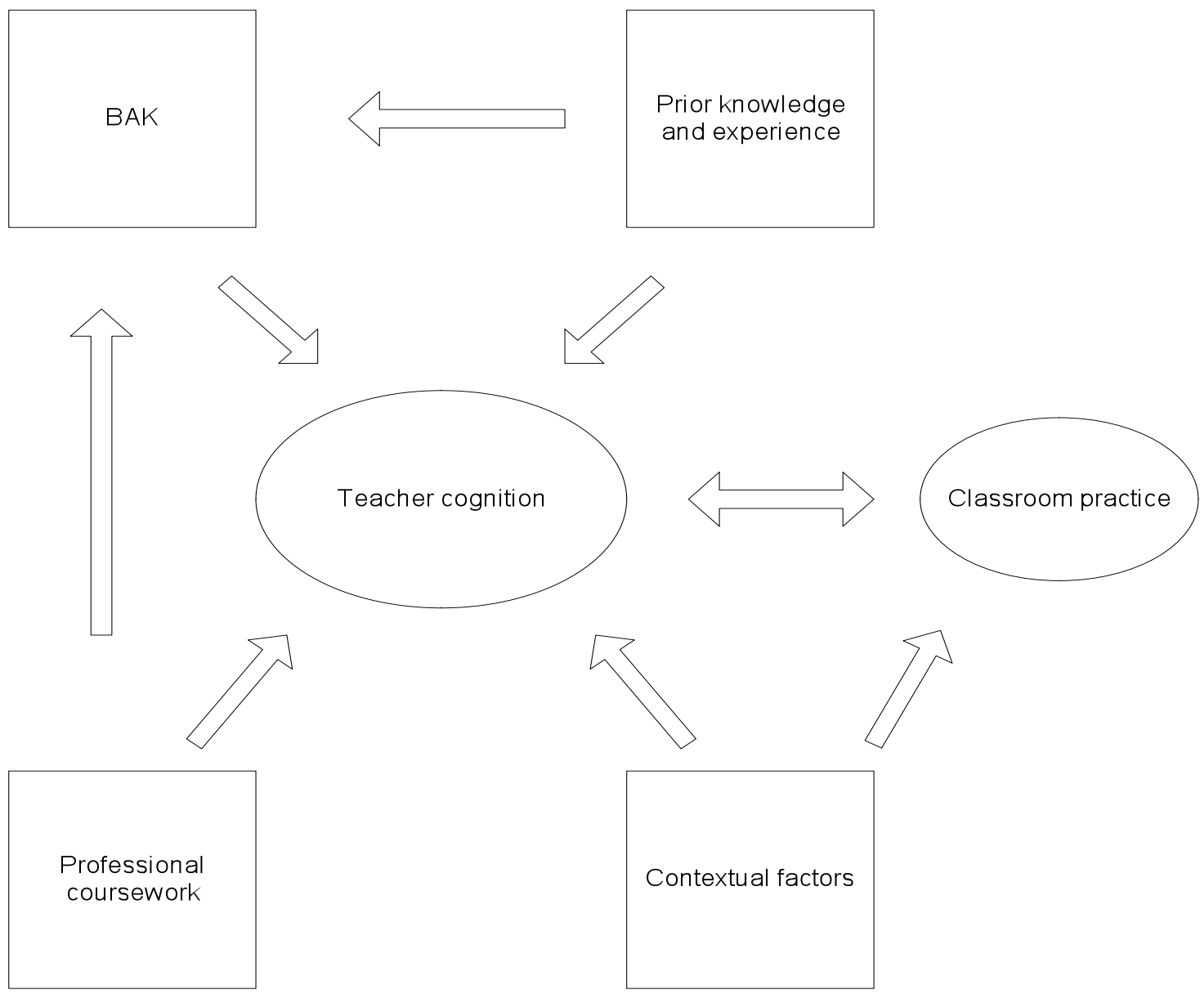

Figure 1. The dynamic nature of teacher cognition (Macalister, 2010)

Within this model of teacher cognition, the influence of the two sets of trainers is most likely to be felt in the professional coursework that the trainees in this study receive. Depending on the way in which the training is delivered, there may also be some input through previous experience, such as experiencing particular teaching activities in workshop situations. When different approaches to language learning / teaching are promoted, trainees may need to negotiate between them, and to decide which to adopt. In understanding the development of their teacher cognition, therefore, it is necessary to investigate the beliefs and attitudes of the teacher trainers themselves. As a result, an initial research question in this study is:

What are the similarities and differences between the beliefs and attitudes of Malaysian and New Zealand teacher trainers in their approach to language teaching?

In this paper, the question is focused further, by limiting the investigation to one type of text. Thus, the question this paper addresses is: 
What are the similarities and differences between the beliefs and attitudes of Malaysian and New Zealand teacher trainers in their approach to teaching an information text?

\section{Methodology}

Sixteen Malaysian and six New Zealand-based trainers volunteered to participate in this study. All twenty-two taught the trainees on core papers in their degree; fewer overall were involved in these mandatory courses in New Zealand than in Malaysia.

Data was gathered from the trainers through questionnaires and semi-structured interviews. As part of the interview, a trainer was presented with an information text (see appendix), and asked how they might use it with an upper primary or lower secondary class. They read the text and when they indicated they were ready began to talk about how they might use the text. Before they did so, the fact that there were no "right" answers was emphasised.

After the interviews were recorded, they were then transcribed and checked for accuracy. Then the transcripts were coded; the codes were a shorthand way of describing what was said. An example of a short coded extract from one interview is shown in Figure 2. Note here and elsewhere in this discussion that the anonymity of the trainers is preserved; each is identified by a randomly assigned letter preceded by a country code, either My or Nz.

Once the interviews had been coded, the process of analysing and drawing conclusions from the data began. In making sense from the data, the dictum for qualitative research proposed by Miles and Huberman (1994) - "you know what you display" - was applied, as will be seen in the presentation of the findings below.

\begin{tabular}{|l|l|}
\hline & JM: Ok, and how will they be reading the text? \\
$\begin{array}{l}\text { DG-TYP-S } \\
\text { RDG-TYP-O } \\
\text { RSN-RDG-O }\end{array}$ & $\begin{array}{l}\text { MyGo reading the text probably this time I'd allow them to read } \\
\text { silently. Ok, after reading silently then probably I would pick students at } \\
\text { correctly and then I may elicit from them, ok we have explained and you } \\
\text { have give me some ideas of this trunk how useful the trunk of this palm } \\
\text { tree is, so now you are reading it, can you understand from the trunk what } \\
\text { we can make out of the trunk or the leaf of the tree? So now you are } \\
\text { reading this paragraph can you tell me what you have said does it } \\
\text { match with what is in the text? So, it's like making sure that what they say } \\
\text { and what is in the text actually is balanced. }\end{array}$ \\
$\begin{array}{l}\text { POST-COMP } \\
\text { WC }\end{array}$ & $\begin{array}{l}\text { JM: Ok, ok, great. So that would be the final activity? That would be the } \\
\text { closing activity / wrap up activity? }\end{array}$ \\
(cf. KWL) & $\begin{array}{l}\text { MyG: No, the wrap up activity would be some comprehension questions } \\
\text { for them to answer, or even like some fill in blank exercises for the weaker } \\
\text { ones. }\end{array}$ \\
\hline $\begin{array}{l}\text { POST-COMP } \\
\text { POST-COMP- } \\
\text { CLZ }\end{array}$
\end{tabular}

Figure 2. Coded interview transcription extract 


\section{Findings}

This paper focuses on three of the areas covered in the discussion about using the information text with an upper primary / lower secondary class. These are:

- how learners are oriented to the text;

- how unknown vocabulary is dealt with; and

- the nature of post-reading activities.

\section{Orientation to the Text}

Thirteen of the sixteen Malaysian respondents discussed the ways in which they would orient their students to this text, and these responses fell into two categories - experience tasks and attention to vocabulary. The full range of responses is displayed in Figure 3 below, with the numbers showing how many respondents discussed that option. Experience tasks "try to narrow the gap [between the learners' present knowledge and the text] as much as possible by using or developing learners' previous experience" (Nation, 2009, p. 95) which can be done in different ways - simplifying or otherwise controlling the text, recalling previous experience, and pre-teaching or experiencing. 


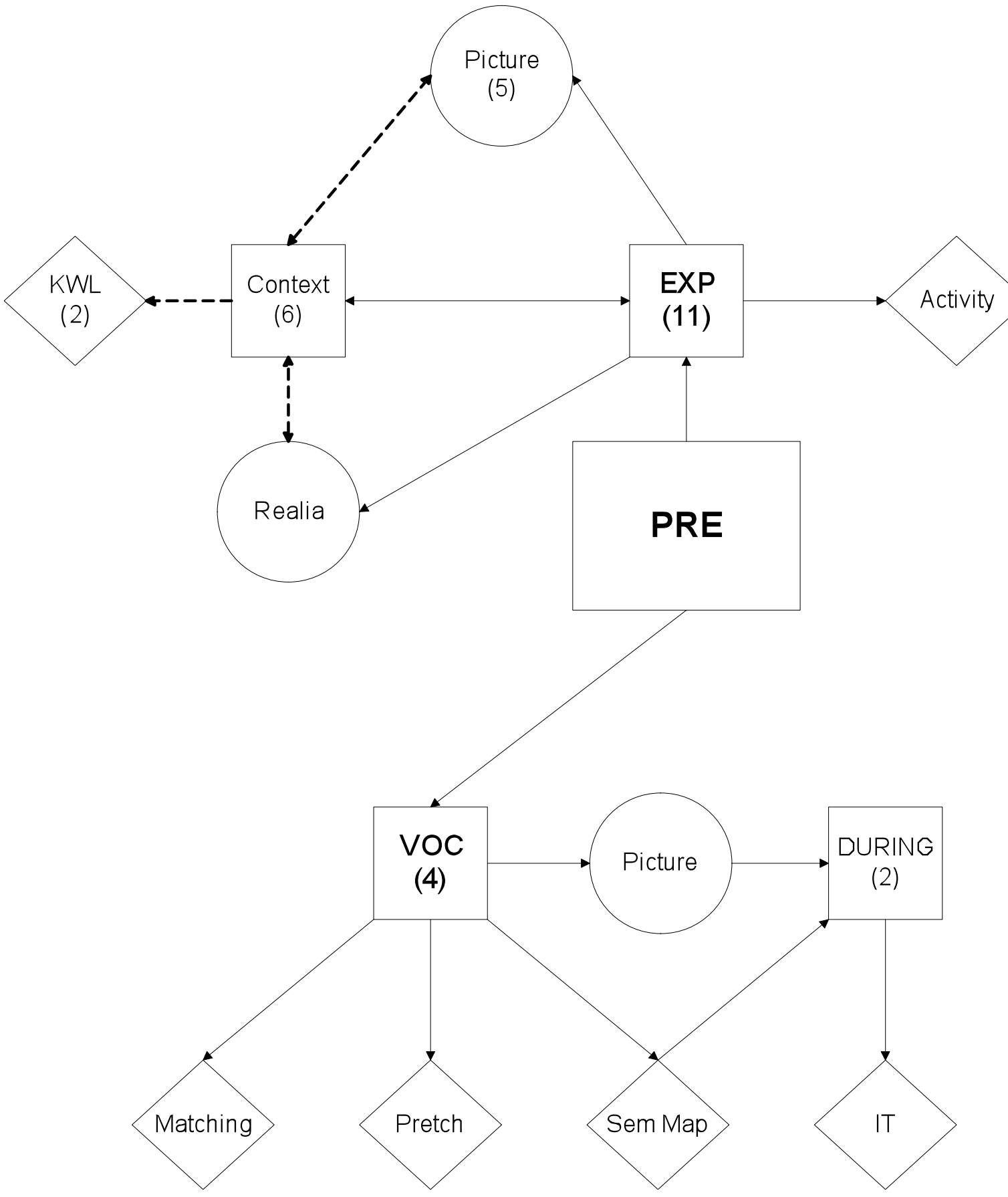

Figure 3. Malaysian pre-reading responses 


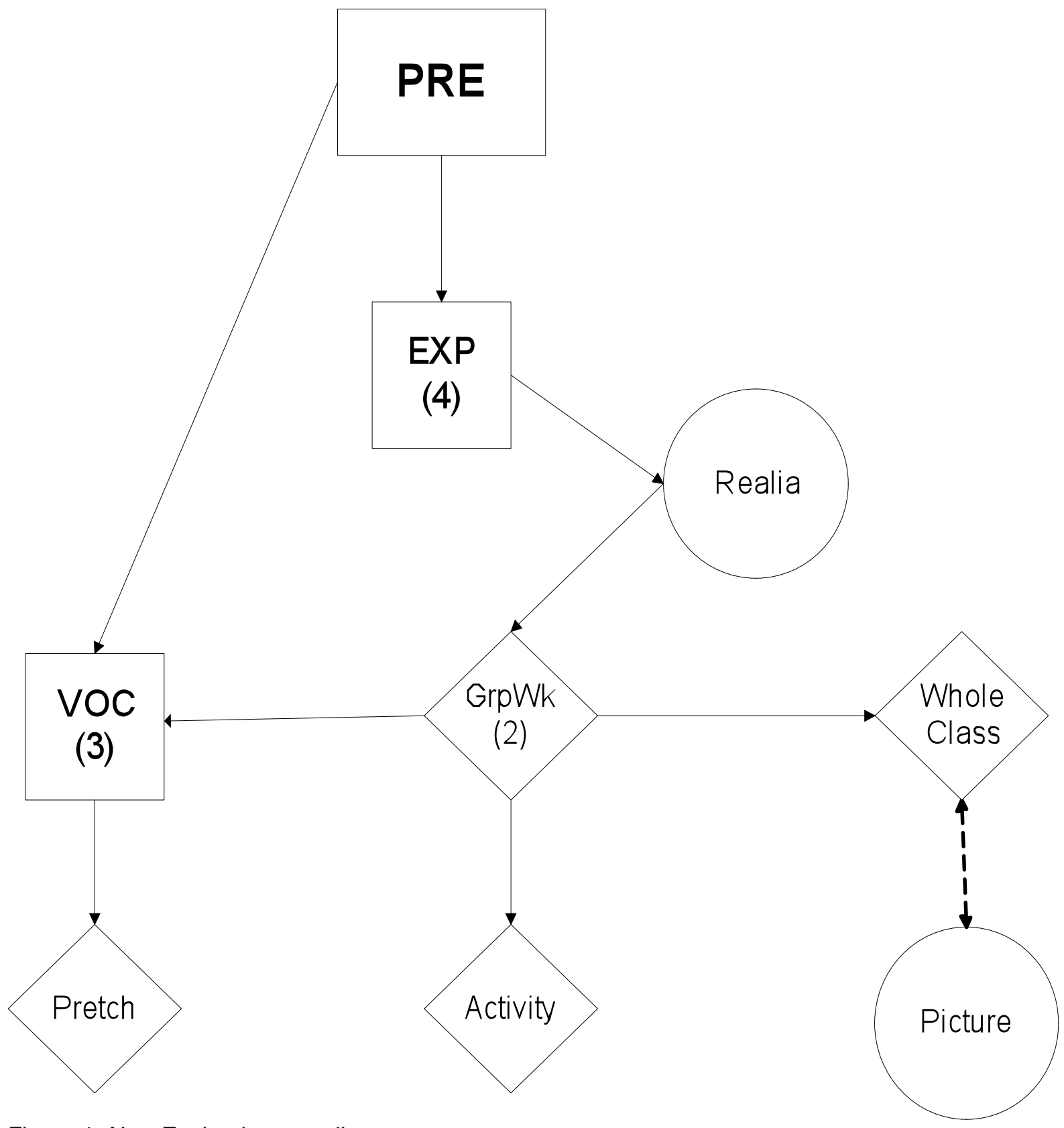

Figure 4. New Zealand pre-reading responses

The trainers recognised that their learners were likely to be familiar with the coconut palm, and that they could draw on this to prepare the learners for reading the text.

So um, again, we talk about a coconut, about coconut trees yeah, and of course they have seen, so ask if they have seen coconut tree, unless, unless I am teaching in a very urban school city for example Kuala Lumpur, Kuala Lumpur, not Penang, Penang they have coconuts ... (MyK)

While acknowledging that learners would be familiar with the coconut from their context, almost half did however mention the use of supporting materials, usually pictures. No matter whether pictures were used or not, the recalling of previous experience tended to be teacherdirected; the teacher focus was often signalled by first-person pronoun use when describing what would be happening. 
Ok, so perhaps I would say, ok, you all know what coconut trees are what are the ... I probably talked about this before going on with the text ... what is the usefulness of the coconut tree? (MyD)

Only one of the Malaysian respondents proposed what might be thought of as a lengthy and student-focused orientation to the text, which included learners producing a poster, and she was alone in giving a clear rationale to this part of the lesson.

Right, so it has been like, ok we know this so well now, we have presented, we have made a poster and we have presented it in class now this is a text and I would think it would be much easier than for them to you know work on understanding. $(\mathrm{MyN})$

As with the Malaysian respondents, four of the six New Zealand respondents who gave attention to this part of the lesson clearly focussed on experience tasks as the means of orientation to the text, as can be seen in Figure 4. Three of the four displayed clear appreciation of the reason for devoting time to this, similar to MyN's reasoning above, and realia and pictures were again mentioned. The greatest difference seemed to be in the manner in which prior knowledge was accessed. Rather than teacher-directed, it was student-focused activity. The students are talking with each other, rather than responding to the teacher in the traditional I-R-E pattern (Cazden, 1988, p. 29).

Um, I would start with the notion of a coconut palm, um, and I would probably start just by asking the class to talk to each other about whether they've ever heard about coconut palms, um, and if so, what they know about it, what they think they know, what ideas they have about it . . . (NzB)

The other noticeable difference between the two groups is in the approach to vocabulary. While only four of the Malaysian respondents gave vocabulary attention in the pre-reading phase, it was even less noticeable among the New Zealand respondents.

\section{Vocabulary}

In the interviews, how teachers might approach unknown vocabulary was often not mentioned, or only mentioned in response to a deliberate question. Among the Malaysian respondents, the lack of attention given to vocabulary was sometimes explained in the following terms. Either the vocabulary was not seen as difficult, or there was not time available in the lesson being envisaged.

... and also to find out if they have their words that they wouldn't know but here I think most of it they will know, except maybe toddy, they will not know and um copra maybe, or husk. (MyF)

Um, yes, I think um, I should also go through some vocabulary with them. But um, it depends on whether there is time; if not then maybe it will be another session on just vocabulary work. (MyO)

For those who did mention vocabulary, there was a diversity of response, with unique mentions for many things. Attention could be given at different stages of the reading process (pre-, during, post-) and a range of ways of dealing with unknown words was employed. These included pre-teaching difficult words, guessing from context, and using dictionaries. Apart 
from pre-teaching, the identification of unknown items was largely student-driven in that any unknown word could be nominated for explanation, with only one trainer suggesting that students did not need to know every word in the text. Indeed, that trainer saw an affective disadvantage to an emphasis of understanding every word.

... yeah, because our students are quite text bound, so they'll read every word and they'll start possibly even pointing in the weaker students pointing to every word and then this is also um, to me it would be very de-motivating in that sense yeah. And every word is quite difficult so here trying to um emphasise how to focus on reading is not so tedious yeah, so you can also focus on chunks of words and those kinds of things. (MyB)

Occasionally the idea that students could learn from others was mentioned, and the notion that vocabulary learning was an additive process was recognised by a number of the Malaysian trainers, whether seen as simply adding new words to a semantic map while reading, or learning a new form for an already known concept.

... because there are some things that the students won't know so like for example, we can eat the white meat to some students meat is the meat, from animals in that sense so what is white meat, so this is, this is good, this is good for them to look at white meat, make cream by grating and pressing it. (MyB)

$\mathrm{Hmm}$, (pause) and maybe because they have the background already, maybe they can learn a few new vocabularies in English. Ah, like, for example, um, what do you call, parts of the coconut palm you know, maybe they know that in Bahasa Malay, in Malay English but they do not know this in English, so this is more like translating from English, I mean sorry from Malay into English. (MyE)

The New Zealand trainers also gave attention to vocabulary at different stages and in a range of different ways but overall appeared to give much less attention to unknown vocabulary than their Malaysian counterparts. This can be seen by comparing the comments about preteaching vocabulary, which was mentioned once in each group of trainers. While the Malaysian trainer said

I think I'd probably use the same method looking at difficult words or other words I think they'll have problems with, dealing with those words and then going through (pause) reading the lesson. (MyD)

the one New Zealand trainer who mentioned pre-teaching limited attention to just one phrase:

I might pre-teach coconut palm, I mean if I saw that you know, you had a barrier to the whole text, ... But I think, you know, you've got to say, yeah ok, it's a bit of a waste of my time but in fact we can't deal with the content unless we can deal with that. (NzE)

Decisions made about vocabulary by this group seemed to be determined by students' demonstrated need to know, and teacher judgment about the usefulness of the unknown word for future learning, an impression illustrated by the following two comments. 
Um, at the point of which we went to jigsaw where they're becoming expert groups, at that point I would do vocab work if a group said to me this talks about hair oil, what is it? We don't know what hair oil is, or this talks about husks, we don't know what husks are. Then I would work with them at understanding, but they would need to tell me they needed to know that. (NzB)

... but you don't want to be, for example, focussing on words like husks, because husks has no value to students. (NzF)

\section{Post-Reading Activities}

Among the Malaysian trainers suggested activities following the reading of the text were noticeably greater than for pre-reading or for the treatment of vocabulary (vocabulary is excluded from consideration in this section although, as mentioned above, it could be treated in post-reading). Typically, a respondent discussed more than one possible post-reading activity, often as alternatives rather than as integrated steps in a learning cycle. At the same time, however, the majority of Malaysian trainers spoke of three main types of post-reading focus: comprehension, graphic organisers, and writing.

Attention to comprehension of the text through comprehension questions was, perhaps, not surprising. Indeed, the fact that "the death by comprehension questions syndrome" (Day \& Park, 2005) was notably absent from responses is worth drawing attention to. Furthermore, when specific forms of question type were mentioned, they included student-generated questions and the K-W-L technique, which in turn suggested thoughtful integration with orientation to the text. (In this technique, learners begin by identifying what they already know (K) about a topic and what they would like to know (W), and conclude by identifying what they have learned (L) from the text.)

Graphic organisers were also mentioned frequently, sometimes with an explicit link to monitoring learners' understanding of the text.

The uses of the coconut palm get them to come up with a graphic organiser so that ah, they understand what the text is about. (MyA)

The graphic organiser was a form of information transfer, and took the form of either a flow chart or a spider diagram / mind map, and was sometimes linked to awareness of text structure.

... I will tell them that the main points are the skeleton for the whole reading passage, so they have to identify the thesis statement and topic sentences, so they build up and another graphic organiser with the thesis statement and the main points. (MyL)

The third common type of post-reading focus was writing, with learners being asked to write, typically, either a comparative text or a similar text about a different plant.

Meaning-focused output tasks were also commonly mentioned by the New Zealand trainers, with oral and written output tasks being identified by equal numbers of respondents (four of the six). Similarly, there was a clear focus on embedding the lesson in a larger unit of work, with four trainers again mentioning this. 
I think I would um, I would embed this text in a bigger kind of a topic maybe on coconuts or on whatever so that they're actually perhaps ready, or you've, you know, it's all building together um, and what you've done before and what you're gonna do will all um, support each other, and that's some kind of written text or something can come from it. $(\mathrm{NzC})$

Although understanding the text was clearly important to this group, there was no mention of comprehension questions as a post-reading activity, nor of graphic organisers (although one envisaged a "spider diagram or something like that").

\section{Discussion}

The first point to make is that in both groups of trainers there was a range of responses. It is certainly not a case of saying all New Zealand trainers would do this or all Malaysian trainers would do that. There are, however, tendencies within each group, and this discussion looks at what appears to be generalisable. Sometimes the tendencies in the two groups are similar, and sometimes they are different. This was also the case in the questionnaire responses. The key similarities and differences about the teaching of this information text that emerged in the interviews are shown in Table 3.

\section{Table 3}

Key Similarities and Differences Between Malaysian and New Zealand-Based Trainers

\begin{tabular}{|l|l|l|}
\hline Phase & Points of similarity & Points of difference \\
\hline Orientation to text & $\begin{array}{l}\text { Strong preference for experience } \\
\text { tasks, drawing on prior knowledge, } \\
\text { possibly supported by pictures / } \\
\text { realia }\end{array}$ & $\begin{array}{l}\text { Group work more likely to be used } \\
\text { by New Zealand trainers as a way } \\
\text { of accessing prior knowledge }\end{array}$ \\
\hline Vocabulary & $\begin{array}{l}\text { Attention given at different stages } \\
\text { of the reading cycle, employing a } \\
\text { range of different approaches } \\
\text { focussing on both strategies (e.g., } \\
\text { guessing from context) and } \\
\text { learning new words } \\
\text { The way in which the text is read, } \\
\text { and the goal(s) in using the text } \\
\text { contribute to the way in which } \\
\text { vocabulary is treated }\end{array}$ & $\begin{array}{l}\text { Use of peers more obviously used } \\
\text { by Neare emphasis on selecting useful } \\
\text { words to give attention to }\end{array}$ \\
$\begin{array}{l}\text { Range of different possibilities } \\
\text { envisaged, with a focus on } \\
\text { meaning / understanding the text } \\
\text { generally present }\end{array}$ & $\begin{array}{l}\text { Malaysian trainers more likely to } \\
\text { focus on comprehension questions } \\
\text { New Zealand trainers more likely } \\
\text { to view the lesson as part of a } \\
\text { larger unit of work }\end{array}$ \\
\hline
\end{tabular}

The interesting question that arises is why these differences in particular exist. To some extent, the differences can be explained simply by acknowledging the influence of context. The particular New Zealand university's research context, for instance, with its strong vocabulary focus, is reflected in the research-informed approaches to language teaching 
coming through in the responses of the New Zealand trainers. Similarly, it was clear that the Malaysian trainers were often referencing their own teaching experience (which tended to be both more recent and more relevant to the future teaching contexts of the trainees than that of the New Zealand trainers), to education in Malaysia, and to the local physical environment. By contrast, the New Zealand trainers' actual language teaching experience tended to be temporally distant and knowledge and / or experience of the Malaysian education system was virtually non-existent.

It may be, however, that underlying any surface differences attributable to physical context, it is possible to discern deeper causes. One such may be indicated by comparing the following two extracts. In the first, a Malaysian trainer is explaining the use of a term that occurred repeatedly in different interviews.

JM: What do you mean by set induction?

MyK: Here we call it set induction, when you begin, when you want to begin a lesson you just tap their previous knowledge, yeah, bring it in that lesson that way you are tuning them to the lesson, so any activities pertaining to that are a set induction.

In the second extract, a New Zealand-based trainer is talking about different ways in which the text could be used, and then decides that a particular approach is the most suitable for this particular text.

So that would be um, and you could do all sorts of communicative activity, well this would, this would be great for . . . in fact that'd be the obvious way to deal with this one. $(\mathrm{NzD})$

One possible interpretation for the difference here is that the first is applying a method, one decreed by the curriculum, and one that would be applied to any text, whereas the other is being text-responsive, considering the nature of the text and the learning opportunities it presents before deciding how to approach it.

In a related vein, a clear impression from the interviews was that interaction, negotiation, and group work were greater features of the New Zealand trainer responses than of the Malaysian. The former tended to be more student-centred, the latter more teacher-centred. This may relate to different conceptions of the role of the teacher, which again comes back to context. Perhaps in Malaysia there has been less challenge of "the core notion of teaching as transmission" (Freeman, 2002, p. 2) than there has been in BANA environments in recent decades. It may also, however, relate to a different understanding of the language learning process and in particular the Vygotskyan notion of learning "being embedded within social events and occurring as a child interacts with people, objects, and events in the environment" (Kublin, Wetherby, Crais, \& Prizant, 1998, p. 287).

\section{Conclusion}

This paper has provided a taste of what the interviews with Malaysian and New Zealand-based trainers reveal about approaches to teaching, with a focus on teaching one type of text. While there are similarities, there are also differences that suggest the BANA / TESEP distinction (see Table 1) remains valid in at least some respects. The New Zealand-based trainers tended to be more learner-responsive and learner-centred and less curricularly constrained than their Malaysian counterparts. One clear departure from the earlier distinction, however, is an 
absence of grammar-translation. Overall, however, the degree of coincidence between the findings from this investigation and the characteristics of the BANA / TESEP distinction suggests that the similarities and differences between this pairing of trainers are not specific to this particular situation.

It is, therefore, important to record that the idea that BANA enjoys high status and TESEP low status remains a troubling one. When working in a TESEP context, anyone from a BANA background tempted to pass judgment should perhaps bear the following in mind:

I can say, in my role as a teacher trainer, "This worked for me, as a New Zealander, in a New Zealand classroom," or even, "This worked for me, a New Zealander in a Cambodian classroom." What I can never say, and can never from my own experience know, is, "This worked for me, a Cambodian teacher, with Cambodian students, in a Cambodian classroom." (Macalister, 1996)

As a result, a BANA trainer in a TESEP setting may perhaps propose alternative ways of doing, but should never seek to impose. An important question that arises from this investigation, then, is how a BANA trainer wishing to introduce an innovation in a TESEP context can be effective. Two important considerations would seem to be these: first, to develop a sound understanding of the setting and of why current approaches to teaching exist, and second, to establish good communication so that the reasons for change are understood and accepted. In other words, drawing on the language of change theory (Nation \& Macalister, 2010, pp. 177178), it is rational-empirical and normative re-educative rather than power-coercive strategies that are likely to be successful.

It may be, however, that no matter how well planned and well delivered a training programme is, and no matter how convincing the reasons for adopting an innovation, it will be contextual factors that largely determine what actually happens in the classroom (see Figure 1). In this respect, and as an area of ongoing research interest, it will be instructive to track the ways in which the pre-service teachers who are receiving their training in both Malaysia and New Zealand negotiate the differences in beliefs and approaches that they are presented with.

Finally, it is important to emphasise that this paper is not presenting judgments about what works and what does not. Context is central in determining classroom practice in any given teaching / learning situation. At the same time, it is important to develop an awareness of differences that may exist. Such an understanding allows us to prepare for some of the differences in attitude and belief that should be engaged with, if ideas are to be successfully communicated in a teacher training programme such as that described earlier in this paper. It also allows us to be sensitive to differences in any classroom where one approach interacts with the other, and as a result, to be more effective teachers.

\section{Author Note}

John Macalister, School of Linguistics and Applied Language Studies, Victoria University of Wellington, New Zealand.

Correspondence concerning this article should be addressed to John Macalister. E-mail: john.macalister@vuw.ac.nz 


\section{References}

Cazden, C. B. (1988). Classroom discourse: The language of teaching and learning Portsmouth, $\mathrm{NH}$ : Heinemann.

Day, R. R., \& Park, J.-S. (2005). Developing reading comprehension questions. Reading in a Foreign Language, 17(1), 60-73.

Freeman, D. (2002). The hidden side of the work: Teacher knowledge and learning to teach. A perspective from North American educational research on teacher education in English language teaching. Language Teaching, 35(1), 1-13. http://dx.doi.org/10.1017/S0261444801001720

Holliday, A. (1994). Appropriate methodology and social context. Cambridge, England: Cambridge University Press

Holliday, A. (2001). The struggle to teach English as an International Language. Oxford, England: Oxford University Press

Julian, K. \& Foster, D. (2011). Design meeting context: A general English course for Burmese adults. In J. Macalister \& I. S. P. Nation (Eds.), Case studies in language curriculum design. New York and London: Routledge.

Kachru, B. B. (1985). Standards, codification and sociolinguistic realism: The English language in the outer circle. In R. Quirk \& H. G. Widdowson (Eds.), English in the world: Teaching and learning the language and literatures (pp. 11-30). Cambridge, England: Cambridge University Press.

Kublin, K. S., Wetherby, A. M., Crais, E. R. \& Prizant, B. M. (1998). Prelinguistic dynamic assessment: A transactional perspective. In A. M. Wetherby, S. F. Warren, \& J. Reichle (Eds.), Transitions in prelinguistic communication (pp. 285-312). Baltimore, MD: Paul H. Brookes.

Leather, S. (2001). Training across cultures: Content, process, and dialogue. ELT Journal, 55(3), 228-237. http://dx.doi.org/10.1093/elt/55.3.228

Macalister, J. (1996). Meeting the needs and demands for English: English for a French medium programme Paper presented at the English language teaching in Cambodia seminar (pp. 49-54). Phnom Penh, Cambodia: Department of English and Education, Royal University of Phnom Penh.

Macalister, J. (2010). Investigating teacher attitudes to extensive reading practices in higher education: Why isn't everyone doing it? RELC Journal, 41(1), 59-75. http://dx.doi.org/10.1177/0033688210362609

Miles, M. B., \& Huberman, M. (1994). Qualitative data analysis: An expanded sourcebook. Thousand Oaks, CA: Sage.

Nation, I. S. P. (2009). Teaching ESL/EFL reading and writing. New York and London: Routledge.

Nation, I. S. P., \& Macalister, J. (2010). Language curriculum design. New York and London: Routledge/Taylor \& Francis. 


\section{Appendix \\ Information Text}

\section{The Coconut Palm}

The coconut palm is one of the most beautiful trees in the world. It is also one of the most useful. For hundreds of years people got their food and drink and their houses from parts of the coconut palm. They used fans and baskets which they wove from the coconut fronds. They made soap and hair oil from coconut oil, and string and mats out of the fibre in the husk.

The coconut tree provides useful building material. The trunk can be used as a post or a rafter; the mid-rib of the leaf makes good walls and floors and we can also make the roof out of the frond.

The palm also provides fuel for cooking. Dry husks burn very well and fishermen use dried woven fronds as torches when they go fishing at night. Even the grey ash left behind after a fire is useful. It is good fertilizer and helps plants to grow bigger if we spread it on the soil.

The tree also provides food and drink. We can drink milk from the green coconut. We can eat the white meat or make cream by grating and pressing it. Children often drink toddy which comes from the flower-stem of the coconut tree. This juice contains many of the vitamins that a human being needs. It helps to make the child healthy and strong.

Today the coconut palm is very important for one other reason. We get copra from the coconut. We can sell copra and this brings money to buy things like petrol, timber, tools, machines, clothing, and vehicles. 